\title{
EDUCAÇÃo PATRIMONIAL, HISTÓRIA PÚBLICA E ENSINO: ANÁLISES E POSSIBILIDADES PARA A HISTÓRIA
}

Jaqueline Ap. M. Zarbato ${ }^{1}$

Joana Carolina Schossler ${ }^{2}$ Aline Vieira Carvalho ${ }^{3}$

\begin{abstract}
Resumo: Este artigo propõe refletir sobre as concepções da Educação Patrimonial e seu entrelaçamento com a História Pública nas proposições para o ensino de história no tempo presente. As concepções teórico-metodológicas de ensinar com o uso da Educação Patrimonial contribuem com as construções de identidades, de narrativas e de formação da consciência histórica, baseando-se nas concepções da educação histórica. E a perspectiva da História Pública que redimensiona o ensino em diferentes espaços educativos, aprofundando as utilizações de fonte e conceitos históricos. A problematização da história pública propõe a ampliação das ações históricas, com engajamento e utilização das fontes em diferentes espaços de produção do conhecimento histórico. Desde a análise dos meios e tipos de produção audiovisual em museus, internet, visitas guiadas pelas cidades, fundamentando o senso crítico e político no tempo presente.
\end{abstract}

Palavras-chave: Educação Patrimonial, História Pública, Ensino de História, Teoria de História.

\section{HERITAGE EDUCATION, PUBLIC HISTORY AND TEACHING: ANALYSIS AND POSSIBILITIES FOR HISTORY.}

\begin{abstract}
This article proposes to reflect on the conceptions of Heritage Education and its intertwining with Public History in the propositions for teaching history in the present time. The theoretical methodological concepts of teaching with the use of Heritage Education contribute to the construction of identities, narratives and the formation of historical consciousness, based on the concepts of historical education. It is the perspective of Public History that resizes teaching in different educational spaces, deepening the uses of historical sources and concepts. The problematization of public history proposes the expansion of historical actions, with engagement and use of sources in different spaces for the production of historical knowledge. From the analysis of the means and types of audiovisual production in museums, internet, guided tours through the cities, basing the critical and political sense in the present time.
\end{abstract}

Key words: Heritage Education, Public History, History Teaching, History Theory.

\footnotetext{
${ }^{1}$ Docente do Programa de Pós-Graduação em Educação na UFMS/CPTL e no ProfHistória da Universidade Federal de Mato Grosso (UFMT). Doutora em História pela Universidade Federal de Santa Catarina (UFSC). Pós-Doutora em História pela Universidade Estadual de Campinas (Unicamp). Professora adjunta na Universidade Federal de Mato Grosso do Sul (UFMS). E-mail: jaqueline.zarbato@gmail.com.

${ }^{2}$ Doutora em História pela Universidade Estadual de Campinas (Unicamp), com estágio sanduíche na Universitè Paul Valéry - Montpellier III, França (2014-2015). Pós-doutoranda na Unicamp.

${ }^{3}$ Professora dos Programas de Pós-Graduação em Ambiente e Sociedade (NEPAM/IFCH/Unicamp), em História (IFCH/Unicamp) e no Mestrado Profissionalizante em História (ProfHistória/IFCH/Unicamp). Doutora pelo Núcleo de Estudos e Pesquisas Ambientais (Nepam/ IFCH/Unicamp).
} 


\section{EDUCACIÓN PATRIMONIAL, HISTORIA PÚBLICA Y ENSEÑANZA: ANÁLISIS Y POSIBILIDADES PARA LA HISTORIA}

Resumen: Este artículo propone reflexionar sobre las concepciones de la Educación del Patrimonio y su entrelazamiento con la Historia Pública en las propuestas para enseñar historia en la actualidad. Los conceptos teóricos y metodológicos de la enseñanza con el uso de la Educación del Patrimonio contribuyen a la construcción de identidades, narrativas y la formación de la conciencia histórica, basada en los conceptos de la educación histórica. Es la perspectiva de la Historia Pública la que redimensiona la enseñanza en diferentes espacios educativos, profundizando los usos de fuentes y conceptos históricos. La problematización de la historia pública propone la expansión de las acciones históricas, con la participación y el uso de fuentes en diferentes espacios para la producción de conocimiento histórico. Del análisis de los medios y tipos de producción audiovisual en museos, internet, visitas guiadas por las ciudades, basando el sentido crítico y político en la actualidad.

Palabras clave: educación patrimonial, historia pública, enseñanza de la historia, teoría de la historia.

\section{Educação Patrimonial e História Pública}

A discussão sobre Educação Patrimonial na História contribui para as possibilidades de diferentes leituras e intepretações de fontes históricas, dos espaços culturais, das paisagens, da memória, da produção de narrativas e da constituição da identidade. A Educação Patrimonial pode ser compreendida dentro de uma perspectiva de Paulo Freire, como um instrumento de "alfabetização cultural"4, pois possibilita ao indivíduo fazer a leitura do mundo que o rodeia, levando-o à compreensão do universo sociocultural e da trajetória histórico-temporal em que está inserido.

Concebendo as inúmeras composições culturais num Brasil múltiplo, diverso, complexo, que podem favorecer o entendimento sobre pertencimento, estranhamento, valorização, manutenção, salvaguarda, reforço da autoestima dos indivíduos e das comunidades, bem como da valorização das culturas locais e regionais, a Educação Patrimonial pode encaminhar para as investigações destas composições culturais e históricas, seja no âmbito do patrimônio material e imaterial.

\footnotetext{
${ }^{4} \mathrm{O}$ termo "alfabetização cultural" advém das ideias de Paulo Freire, que pensa que "ao discutir sobre o mundo da cultura e seus elementos, os indivíduos vão desnudando a sua realidade e se descobrindo nela". A introdução oficial do termo data dos anos 1980, em uma formação realizado no Museu Imperial do Rio de Janeiro. FILHO; ECKERT; BELTRÃO (orgs.) Antropologia e Patrimônio Cultural. Diálogos e desafios contemporâneos. Nova Letra: p. 82-83. Disponível em: http://livroaberto.ufpa.br/jspui/bitstream/prefix/442/1/CapitulodeLivro_EducacaoPatrimonialPerspectivas.pdf
} 
Nesse processo, a Educação Patrimonial favorece um diálogo permanente entre os agentes históricos, que são responsáveis pela preservação dos bens culturais e as concepções educativas, numa vinculação em relação ao intercambio de conhecimento em diferentes espaços de saber. Visando o entendimento de que as formas de proteção e preservação de bens culturais devem ser relacionadas à ciência histórica no cotidiano das pessoas, e pensando os patrimônios como bens públicos e de uso público, o patrimônio é, portanto, uma forma de História pública, "porque assume os discursos das coisas que são de todos, para a fruição de todos e para o bem de todos" (MENESES, 2018, posição 121).

Entrelaçar a História Pública com a Educação Patrimonial como proposição para diferentes formas de ensinar e aprender História, bem como de construir memórias e gerar sentidos patrimoniais (MENESES, 2018, p. 1212), envolve o conhecimento de conceitos históricos e de diferentes fontes e metodologias de pesquisa. Em que a divulgação de temas de interesse da comunidade de leitores e ouvintes possibilita organizar o conhecimento, compreender e desenvolver noções de tempo e espaço, gerando uma consciência de si enquanto sujeito histórico. Em vista disso, a História Pública "se preocupa com as produções de sentido sobre o passado, originadas da historiografia especializada e das produções acadêmicas, com as quais os historiadores se relacionam com comunidades, com a preservação histórica e com sítios históricos (BENAVIDES; ÁLVAREZ, 2019, p. 301-302) aliando as produções acadêmicas aos espaços de diálogo construtores de uma história que contribui com a formação da memória e da consciência histórica.

As dimensões de leitura de mundo e de alfabetização cultural, com o uso de metodologia da Educação Patrimonial que, pode ser aplicada a qualquer evidência material ou manifestação da cultura, seja um objeto ou conjunto de bens, um monumento ou um sítio histórico ou arqueológico, uma paisagem natural, um parque ou uma área de proteção ambiental, um centro histórico urbano ou uma comunidade da área rural, uma manifestação popular de caráter folclórico ou ritual, um processo de produção industrial ou artesanal, em tecnologias e saberes populares.

Esse é um dos desafios da educação patrimonial para com o ensino de história, constituindo-se num instrumento de conhecimento das culturas no mundo que nos cerca e de nossas relações com nosso ambiente. Ou como define o documento "Educação Patrimonial:

\footnotetext{
5 BENAVIDES; Amada C. P. \& ÁlVAREZ, Sebastian V. Historia Pública e investigación colaborativa: perspectivas y experiencias para la coyuntura actual colombiana. Revista achsc Vol. 46 N. ${ }^{\circ}$ 1, juN. 2019.
} 
Histórico, conceitos e processos", do Instituto do Patrimônio Histórico e Artístico Nacional (IPHAN, 1999)

[...] a Educação Patrimonial constitui-se de todos os processos educativos formais e não formais que têm como foco o Patrimônio Cultural, apropriado socialmente como recurso para a compreensão sócio-histórica das referências culturais em todas as suas manifestações, a fim de colaborar para seu reconhecimento, sua valorização e preservação. Considera ainda que os processos educativos devem primar pela construção coletiva e democrática do conhecimento, por meio do diálogo permanente entre os agentes culturais e sociais e pela participação efetiva das comunidades detentoras e produtoras das referências culturais, onde convivem diversas noções de Patrimônio Cultural.

Discutindo questões relacionadas ao Patrimônio, sua valorização por meio das ações de Educação Patrimonial, julgamos ser importante refletir sobre as questões acerca do processo de patrimonialização apresentada por Hartog. $\mathrm{O}$ autor chamou atenção para tal processo, estabelecendo uma crítica ao fato de que "tudo tornava-se patrimônio" na busca por uma identidade nacional, por símbolos que pudessem contribuir na construção e representação desta identidade.

Em vista disso, podemos pensar o patrimônio como indutor do conhecimento histórico e como um instrumento de ensino, como propõe José Newton Coelho Menezes, ao considerar que as produções acadêmicas e historiográficas, quando se conectam com as possibilidades de patrimonialização, se confrontam com narrativas tradicionais. Como afirma Menezes (2018, p 1289):

No caso do ensino, a discussão do patrimônio estimula um processo de observação, de registro crítico e de busca de significação. Como método pedagógico, a exploração do patrimônio histórico-cultural promove uma apropriação de informações oriundas da pesquisa histórica e as apresenta ao aluno no encontro com a realidade de sua sociedade historicizada. Tal estímulo costuma ser fundamental na indução de habilidades cognitivas, que colocam o estudante frente ao problema histórico concreto, parte de sua vivência, exemplo de sua experiência cotidiana. Dessa forma, o patrimônio estimula a busca de conhecimento da História pela problematização do cotidiano e não pela produção de informações e pela memorização. Por outro lado, acrescenta à observação e à exploração crítica a possibilidade de intervenção através da discussão e da busca de ações de preservação e de salvaguarda.

A abordagem sobre patrimônio histórico, com a metodologia da Educação patrimonial permite que se reconheçam e aprofundem os discursos sobre a História, a Cultura, 
as ações públicas que podem ser mediadas em diferentes espaços culturais, desde as escolas até o convívio social numa comunidade.

Além disso, essa problematização contribuirá com o conhecimento sobre a diversidade cultural, étnica, religiosa e de trabalho articuladas à problemática do patrimônio cultural material e imaterial. Ao falar sobre patrimônio, muitas vezes, as pessoas recorrem ao adjetivo cultural, mas eminentemente deslocam seu olhar para os monumentos históricos, as casas antigas, museus. Entretanto, é necessário ampliar esse olhar, induzindo as percepções de que o patrimônio pode ser passível de leituras de mundo, por parte dos sujeitos e de seus sentimentos de pertencimento ou estranhamento em relação ao patrimônio. É sobre esse processo de consciência histórica, que as vivencias e leituras de mundo podem fazer sentido e serem utilizadas como possíveis fontes documentais constituídas por diferentes linguagens.

O patrimônio pode ser entendido a partir de determinadas condições socioeconômicas de produção de determinado bem histórico, das relações de poder que demonstram que tal imóvel, "por pertencer a uma determinada parcela mais abastada da sociedade, então, foi construído com material de melhor qualidade, pode explicar continuidades e mudanças ocorridas em determinados locais, entre várias outras potencialidades que estes documentos apresentam" (OLIVEIRA, 2008. p. 98).

As culturas constituem-se como elemento norteador das análises patrimoniais, impulsionando as abordagens sobre patrimônio cultural em países da América Latina e, mais especificamente no Brasil, com ações de proteção, investigação, preservação, educação. Advém também, os estudos e abordagens relacionados as áreas da Arquitetura, Antropologia e História. Entretanto, é importante salientar que, "o patrimônio é usado não apenas para simbolizar, representar ou comunicar: ele é bom para agir. Essa categoria faz a mediação sensível entre seres humanos e divindades, mortos e vivos, passado e presente, entre o céu e a terra e entre outras opções" (GONÇALVES, 2009, p 31). Na América Latina, a análise sobre o patrimônio, conforme Quijano (2005, p 110) se deu pela:

A incorporação de tão diversas e heterogêneas histórias culturais a um único dominado pela Europa significou para esse mundo uma configuração cultural, intelectual, em suma intersubjetiva, equivalente à articulação de todas as formas de controle do trabalho [...] Em outras palavras, como parte do novo padrão de poder mundial, a Europa também concentrou sob sua hegemonia o controle de todas as formas de controle da subjetividade, da cultura, e em especial do conhecimento, da produção do conhecimento. 
Tendo em vista a multiplicidade cultural e como uma sociedade constrói o seu patrimônio, cabe pensar em como os processos educativos primam pela construção de uma memória coletiva e democrática do conhecimento. Essas primeiras ideias, apresentadas por Maria de Lourdes Horta, Evelina Grunberg e Adriane Monteiro (1999) a partir da experiência no Museu Imperial, introduziram alguns princípios que devem reger a educação patrimonial, para que seja possível compreender o processo permanente e sistemático do trabalho educacional que utiliza o patrimônio cultural como fonte primária de conhecimento e enriquecimento individual e coletivo. Conforme Horta, Grumberg, Monteiro (1999, p. 05), a partir do entendimento de que os objetos e expressões do patrimônio cultural são ponto de partida para a atividade pedagógica, é possível ampliar esse conhecimento e os dados observados e investigados diretamente, pois:

A partir da experiência e do contato direto com as evidências e manifestações da cultura, em todos os seus múltiplos aspectos, sentidos e significados, o trabalho da Educação Patrimonial busca levar as crianças e adultos a um processo ativo de conhecimento, apropriação e valorização de sua herança cultural, capacitando-os para um melhor usufruto destes bens, e propiciando a geração e a produção de novos conhecimentos, num processo contínuo de criação cultural. A observação direta e a análise das "evidências" (aquilo que está à vista de nossos olhos) culturais permitem à criança ou ao adulto vivenciar a experiência e o método dos cientistas, dos historiadores, dos arqueólogos, que partem dos fenômenos encontrados e da análise de seus elementos materiais, formais e funcionais para chegar a conclusões que sustentam suas teorias. $\mathrm{O}$ aprendizado desse método investigatório é uma das primeiras capacitações que se pode estimular nos alunos, no processo educacional, desenvolvendo suas habilidades de observação, de análise crítica, de comparação e dedução, de formulação de hipóteses e de solução de problemas colocados pelos fatos e fenômenos observados.

As ideias lançadas pelas autoras e legitimadas pelo Instituto do Patrimônio Histórico e Artístico Nacional (IPHAN), com a publicação do Guia Básico de Educação Patrimonial em 1999, entendem que a Educação Patrimonial é “um processo permanente e sistemático de trabalho educacional centrado no Patrimônio Cultural como fonte primária de conhecimento e enriquecimento individual e coletivo. Busca levar as crianças e adultos a um processo ativo de conhecimento, apropriação e valorização de sua herança cultural, capacitando-os para um melhor usufruto destes bens, e propiciando a geração e a produção de novos conhecimentos, num processo contínuo de criação cultural" (IPHAN, 1999, p.7).

\footnotetext{
6 HORTA, Maria de Lourdes; GRUMBERG, Evelina, QUEIROZ, Adriane. Guia de Educação
} Patrimonial/IPHAN, 1999. 
Promover a preservação e valorização desses bens culturais, exige aprofundamento no campo do ensino de História, pois envolve ações educativas que possam viabilizar a aproximação entre os sujeitos que estudam e aprendem, num processo que promova no ambiente vivenciado uma possibilidade de leitura da memória coletiva, dos monumentos e das relações que se estabelecem entre eles, de forma analítica e crítica. Conforme Horta, Grunberg e Monteiro (1999, p. 6):

\begin{abstract}
O conhecimento crítico e a apropriação consciente pelas comunidades do seu patrimônio são fatores indispensáveis no processo de preservação sustentável desses bens culturais, assim como no fortalecimento dos sentimentos de identidade e cidadania. A Educação Patrimonial é um instrumento de "alfabetização cultural" que possibilita ao indivíduo fazer a leitura do mundo que o rodeia, levando-o à compreensão do universo sociocultural e da trajetória histórico- temporal em que está inserido. Este processo leva ao reforço da auto- estima dos indivíduos e comunidades e à valorização da cultura brasileira compreendida como múltipla e plural.
\end{abstract}

Ao traçar um panorama sobre a educação patrimonial, Janice Gonçalves (2014, p 86/87) analisa duas concepções fundamentais sobre as ações educativas acerca do patrimônio cultural. Em seu primeiro apontamento, a autora demonstra como as políticas internacionais criadas ao longo do século XX pela UNESCO e ONU, por meio de documentos, convenções e cartas patrimoniais, definiram "as ações educativas como transmissoras e estimuladoras de respeito, interesse e estima pelo patrimônio cultural", na qual as ações educativas possibilitariam uma "tomada de consciência do público- alvo, tornando, a partir de então uma espécie de parceiro na salvaguarda dos bens culturais patrimonializados.

Já no segundo apontamento, Gonçalves relaciona a aplicação desses documentos internacionais na política brasileira, para qual desde 1970 diferentes compreensões em relação à memória, à cidadania e à valorização de identidades culturais passavam por diferentes instrumentos de reflexão, que valorizavam sobretudo a participação cidadã e as memórias de diferentes grupos culturais e sociais.

Nesse sentido, os monumentos, conjuntos arquitetônicos e lugares notáveis compõem o chamado patrimônio cultural. Um dos elementos que envolvem o estudo do patrimônio cultural na contemporaneidade, se constituem como: “os acervos de tradição do passado são integrados na dinâmica de transformação do presente, sem que necessariamente sejam tolhidos pelo redemoinho dos ininterruptos sobrepujamentos do passado pelo futuro" (Rüsen 2014, p 243). 
Umas das possibilidades que favorece o aprofundamento sobre o conhecimento histórico com a utilização da Educação Patrimonial permite o entrelaçamento da 'valorização' da cultural regional e do patrimônio como fundamento das diferentes interpretações que estudantes e professores/as, que possam conhecer, dialogar, aprender e ensinar sobre a história e a cultura da cidade e da região. Além disso, essa problematização contribuirá com o conhecimento sobre a diversidade cultural, étnica, religiosa e de trabalho articuladas à problemática do patrimônio cultural material e imaterial. E a partir dos métodos da História oral, etnografia e educação histórica fundamentam dois focos importantes: a valorização e preservação da memória regional e patrimônio cultural e a inserção na aula de história com a Educação Patrimonial.

Em vista da interdisciplinaridade, ampara-se a análise da História Pública, a qual tem sua origem nos Estados Unidos nos anos 1970, e ganhou espaço na Inglaterra, Itália, Canadá, Austrália África do Sul e Brasil. Assim, a história púbica ganha um caráter engajado, interrelacionada com a memória e a narrativa, o que contribui para a fundamentação das leituras e releituras de mundo. Nos anos 1980 e 1990, a História Pública expandiu-se e relacionou-se com a memória, o patrimônio e a História Oral. Para Jill Liddington (2011, p 32):

[...] a 'história pública' é um guarda-chuva tão acolhedor a ponto de oferecer abrigo a todas as formas de história 'popular' - seja ela a história oral ou a 'história dos povos', a 'história aplicada' ou os 'estudos do patrimônios'? A resposta, provavelmente, é um generoso 'sim': deixai que mil flores desabrochem.

Com isso, abriga as leituras de mundo por parte dos sujeitos, com sentimento de pertencimento ou estranhamento em relação ao espaço cultural e social em que vivem. Nesse processo, a história pública apresenta-se como campo diverso e sofisticado, podendo se manifestar por meio da educação, o que contribui na orientação de museólogos, arquivistas, cineastas, documentaristas, entre outros profissionais.

Segundo Rodrigo de Almeida Ferreira (2018, p 36/37), desde o surgimento da História Pública no Brasil, em 2011, a escola tem sido um local privilegiado para refletir e produzir uma educação reflexiva e crítica, que pautada no uso de novas ferramentas e suportes, como charges, música, literatura, jogos, patrimônio e museus, estimulam o "conhecimento histórico extraescolar aprendidos em suas trajetórias sociais".

Ao problematizar a circulação e a produção de sentidos da história, produzidos extramuros da Universidade e da Escola, entrelaçamos a perspectiva da História Pública com a 
metodologia da Educação Patrimonial, pois elas fornecem elementos relevantes para a concretização da agenda da cidadania a partir da problematização dos patrimônios.

Os patrimônios podem ser entendidos a partir de determinadas condições socioeconômicas de produção de determinado bem, das relações de poder que demonstram que tal imóvel "por pertencer a uma determinada parcela mais abastada da sociedade, então, foi construído com material de melhor qualidade, pode explicar continuidades e mudanças ocorridas em determinados locais, entre várias outras potencialidades que estes documentos apresentam" (Oliveira, 2008. p. 98).

A busca pela conexão entre o ensinar e aprender História leva em conta as diferentes dimensões subjetivas de alunos/as e professores/as, os quais experimentam na arte da História, o contato com as mais variadas perspectivas historiográficas. Mas, ao analisar a proposição de Jörn Rüsen sobre a experiência e a interpretação, nota-se, muitas vezes, um certo descolamento do sujeito no processo de explicação histórica. Isso porque, a produção de sentido caracterizada pela racionalidade, em algumas atividades da aprendizagem histórica não é problematizada.

Ao fundamentar nossa análise na produção de sentido, entende-se que a intepretação, permite o aprofundamento do que se pretende ensinar na História. Pois, como afirma Rüsen (2013, p 183):

Interpretar é a resposta a essa pergunta desafiadora da contingência. Ela relaciona no tempo experimentado com o senso temporal interior, no qual a subjetividade humana se afirma como interação de memoração e expectativa. Paradigmática para esse feito interpretativo é uma concepção de decurso do tempo que une passado, presente e futuro de tal maneira que o futuro com carga normativa se torna compatível com o passado carregado de experiência e a situação que se abre entre experiência e expectativa, a saber, a situação das circunstâncias presentes da vida apareça como proveitosa para a vida.

Assim, interpretar tem um significado importante para a História, pois amplia o enfoque do passado-presente-futuro, pode-se dizer que é um dos elos na fundamentação da didática da História, estando relacionada também com a orientação, que significa dar uma versão prática a essa interpretação do tempo. Ela é posta em relação com a pressão do sofrimento e a direcionalidade finalista do agir como fator de sua intencionalidade; ela é, por assim dizer, levada à plenitude do seu direcionamento. 


\section{A abordagem da Educação Patrimonial nos espaços públicos: produção de sentindo no ensino de história}

Tendo em vista que os sujeitos históricos obtêm memórias, e que são cidadãos participativos que produzem narrativas e sentidos, normalmente mobilizadas pelo educador, é importante pensar em abordagens possíveis para a educação patrimonial, tendo em vista que a aprendizagem está para além da sala de aula e que se relaciona com os espaços públicos.

Ao analisar as políticas de ações educativas em relação ao patrimônio cultural, Janice Gonçalves (2014, p. 90-93) lança 4 proposições para pensar as práticas de educação patrimonial. A primeira delas trata-se de "desnaturalizar o patrimônio cultural, refletindo sobre o campo que o produz"; ou seja, problematizar e pensar como a noção de "patrimônio cultural" foi historicamente construída e passou a determinar o que o representa e que deve ou não ser preservado. A segunda é "dessacralizar o acervo patrimonial, problematizando os processos sociais e históricos que o engendram"; isto é, reiterar e rememorar continuamente os processos sociais e históricos que geraram a patrimonialização do bem, lembrando que nenhuma ação é suficiente para protege-lo. A terceira proposição é "pôr sob suspeição uma perspectiva do processo educativo que oponha educadores e educandos como esclarecidos e não esclarecidos; para qual as práticas educativas favoreçam o exercício da dúvida e possibilitem o surgimento da atribuição de novos valores. E por último, "valorizar as diversas instâncias que lidam com o patrimônio cultural como produtoras e disseminadoras de saberes e visões sobre ele e buscar compreender suas especificidades”, isto é, considerar a interdisciplinaridade e suas ações no campo da institucionalização do patrimônio.

Tendo em vista essas quatro dimensões lançadas por Gonçalves, podemos então pensar em como aplicar uma Educação Patrimonial em espaços públicos, considerando igualmente o ensino de História ligado à História pública em espaços patrimoniais. Partindo da perspectiva que a História pública transcende a linguagem acadêmica e se utiliza de outros suportes e linguagens colaborativas, abertas e inclusivas para a produção de conhecimento histórico, o desafio é pensar em como a educação patrimonial pode ser aplicada a este caso.

Ao repensar a relação do historiador com a sociedade e perceber como a mesma tem se apropriado da história, os profissionais têm criado novas possibilidades de atuar e expandir o conhecimento histórico, sendo uma das possibilidades apresentadas, os passeios ou visitas guiadas pelas cidades históricas. Essa atividade que até então era oferecida por profissionais do turismo ou por curiosos e amantes da história, agora tem se tornado uma possibilidade de trabalho para o historiador então denominado público, e que leva para o âmbito da atividade 
os questionamentos e os conhecimentos históricos, democratizando os processos de reflexão sobre o passado (BENAVIDAS; ÁLVAREZ:2019, p. 305).

Pensando que nesses espaços públicos encontram-se diferentes tipos de patrimônio, como por exemplo, praças, monumentos, sítios arqueológicos, manifestações culturais, prédios e fachadas arquitetônicas, é preciso estabelecer um objetivo claro em relação ao roteiro de saída de campo, de modo que permita aos participantes produzirem sentidos por meio da experiência e o contato com esses espaços.

A definição do objetivo possibilita, igualmente, enfatizar e problematizar as categorias pelas quais se analisa o passado, visando as proposições oferecidas por Gonçalves. Para deixar mais claro, podemos analisar o exemplo da estátua de João Cândido Felisberto, líder da Revolta da Chibata (1910), situada na Praça XV, no Rio de Janeiro, inaugurada em 2008 e localiza nesse espaço público, histórico e de grande circulação.

A estátua representa um monumento artístico e histórico, que quando elucidada ao público, não pode oferecer a reprodução de informações escolares ou uma falta de problematização. Ou seja, o contato ou reaproximação com esse monumento, precisa despertar no sujeito uma consciência histórica que possibilita uma nova narrativa. Para isso, é importante então pensar por que aquela estátua está ali, e, hoje, praticamente escondida entre as paradas e trilhos do VLT Carioca. Indo além, também cabe indagar quais são as disputas que permeiam a história representada por meio desse personagem? Qual sua importância histórica? Por que ela está inserida naquele espaço? Em que contexto que essa estátua foi colocada ali? Quais são os discursos que constituem a memória desse momento ao longo do tempo?

Perguntas como essas, mobilizam os participantes a buscarem mais conhecimento sobre os aspectos históricos, sem se restringirem ao conhecimento disponível no livro didático ou a estarem passivos, em contato com informações técnicas ou superficiais. Além disso, como sinaliza Ricardo Oriá (2018, p 34), a relação dos monumentos históricos com a História Pública permite reformular a "prática da construção de monumentos aos heróis como um instrumento usado para criar entre os cidadãos um sentimento de pertencimento ao estado nacional e desenvolver uma consciência cívico-patriótica que começava na escola, mas que deveria se estender a outros públicos da cidade". Essa sinergia entre documentos, procedimentos historiográficos e história pública, é analisada por Benavidas e Álvarez (2019, p 305) que consideram: 
A necessidade de explicitar as perguntas de investigação, as fontes, os métodos e as categorias das quais se analisa o passado, assim como a busca de formas narrativas distintas, têm ampliado os públicos da história, uma vez que se espera desses uma aproximação crítica as interpretações que os historiadores propõem. Neste sentido, se tem pensado o lugar social dos historiadores e a pertinência de seu ofício, deixando de concebê-los como detentores da verdade sobre o passado a sua configuração como interpretes que buscam, por meio de métodos e teorias explicitas, interpelar as sociedades de que fazem parte e deixar-se interpelar por elas com base em perguntas colocadas ao passado a partir de problemáticas e tensões do presente

Ainda em relação as visitas guiadas pelas cidades, quando se trata de fachadas de prédios históricos ou de práticas culturais, perguntas semelhantes podem ser formuladas. Além disso, é importante pensar quais foram os processos de patrimonialização desses bens imateriais e materiais? quais são os valores atribuídos e quais foram as disputadas que se relacionam com o espaço onde estão inseridos? Também cabe fazer o uso de documentos históricos, como imagens e cartografias, pois elas permitem ter uma ideia da transformação do espaço urbano ao longo do tempo e os impactos em relação ao valor daquele patrimônio.

Quando pensamos que o contato e a problematização em relação a história e as fontes históricas geram um sentido, que para Rüsen (2014, p 259), está pautado na experiência de poder vivenciar o passado, o presente e o futuro; essa vivência atualiza a narrativa de si e do mundo, formando a consciência histórica de si enquanto sujeito histórico apropriado do espaço. Em vista disso, podemos pensar que o contato com esse patrimônio e sua educação patrimonial, produz o sentido de uma vivência que permite reformular a narrativa em relação ao elemento patrimonial pouco observado pelo público.

O mesmo efeito pode ser observado em relação às linguagens audiovisuais criadas especificamente para museus ou para sites da internet e aplicativos relacionados à cultura. Atualmente, a maioria das instituições museológicas já possuem a possibilidade de visitas guiadas ou a visualização de elementos presentes em exposições.

O impacto das tecnologias está a implicar alterações profundas no modo como se transmitem as informações e como se constrói o conhecimento, possibilitando também uma reconfiguração e reorientação dos procedimentos através dos quais se estuda, recupera e difunde o património. O património já não está localizado unicamente em espaços físicos, mas as oportunidades que a rede Internet oferece possibilitam uma alteração dos meios de apresentação, preservação e difusão do legado histórico- educativo do nosso passado pessoal e coletivo, através do uso de plataformas e espaços virtuais para a aprendizagem nos processos de ensino- aprendizagem (JIMÉNEZ- RAMÍREZ; DEL POZO SERRANO, 2016, p. 42-43). 
Outro fator interessante é a utilização do audiovisual enquanto fonte documental, na qual o participante, ao ter contato com a exposição, deixa registrado em vídeo sua narrativa formulada a partir do contato com aquelas experiências de aprendizagem para a memória coletiva e o desenvolvimento sociocultural e histórico-social a partir da educação (JIMÉNEZ- RAMÍREZ; DEL POZO SERRANO, 2016, p. 38 e 43).

Além disso, o audiovisual também possibilita explorar a aprendizagem por meio de outros sentidos. Ela pode conectar ou complementar possibilidades que o percurso narrativo da exposição não compreende, demonstrado com clareza elementos sonoros ou de práticas culturais que fazem parte das culturas. Em vista disso, como aponta Paulo Knauss (2018, p. 2545).

[...] os museus também enfrentam os desafios de se dirigirem para o seu grande público em busca de conquistar novas audiências. Com frequência, fazem uso de estratégias de mobilização social para construir com seu público a interpretação e a leitura de seus acervos e coleções, num movimento colaborativo de reconhecimento de autoridade compartilhada. Ao lado disso, é evidente a emergência dos museus comunitários e as expressões de museologia social, além de contribuírem para inovar os modelos de museus, representam igualmente museus feitos pelo público, substituindo o protagonismo dos profissionais e do discurso técnico. Essas tendências gerais caracterizam o destaque atual da dimensão reflexiva e autoreflexiva sobre o universo dos museus e seus públicos.

Nesse sentido, fundamentar as abordagens entrelaçadas entre educação patrimonial, história pública e ensino de história nos encaminha a problematizar as ações possíveis no campo da museologia, por exemplo. Uma vez que inserimos as dimensões de leitura e interpretação de mundo, a partir das coleções, exposições, acervos, documentos, edificações, entre outros. Assim, o processo de construção de uma narrativa que envolve os diferentes sujeitos, de diferentes culturas e com apreensão sobre o significado de patrimônios em suas trajetórias de vida, pode ser explorado como uma proposição interdisciplinar. O qual se envereda por múltiplos diálogos sobre o que representa e de que forma é representado determinado acervo em museus, que memórias querem narrar, que vestígios históricos são problematizados. Isso é um dos percursos do ensino com a Educação Patrimonial, que pode ser explorado, projetando novas experiências na produção de sentido histórico.

A inserção da análise realizada a partir da Educação Patrimonial permite desenvolver e aprofundar concepções que estão imersas na História Pública, mas não no âmbito contemplativo e, sim como forma de perceber as rupturas e permanências nas trajetórias culturais e sociais. Uma vez que, ao adentrar no museu, pode-se com o encaminhamento 
metodológico da Educação Patrimonial e história pública dispor de ferramentas que formulem diferentes narrativas e que contribuam para a ampliação das analises criticas, que produzem uma investigação dialógica e compartilhada do conhecimento histórico.

Em suma, a pretensão do artigo em atrelar as discussões da Educação Patrimonial e história pública, teve como intuito provocar reflexões sobre as ações de ensino, não somente no campo metodológico, mas também como constructo teórico. O qual favorece a percepção de um ensino que utilize espaços como os museus no aprofundamento sobre a produção de sentido histórico.

\section{Referências}

ALMEIDA. Juniele Rabêlo; ROVAI, Marta Gouveia de Oliveira (Orgs.). Introdução à História Pública. São Paulo: Letra e Voz, 2012.

BENAVIDES, Amada Carolina Perez; ALVAREZ, Sebastian Vargas. "Historia Publica e investigacion colaborativa: perspectivas y experiencias para la coyuntura actual colombiana", Anuario Colombiano de Historia Social y de la Cultura 46.1 (2019):

CHUVA, Márcia. O ofício do historiador: sobre ética e patrimônio cultural. In: INSTITUTO DO PATRIMÔNIO HISTÓRICO E ARTÍSTICO NACIONAL. Anais da I Oficina de Pesquisa: a pesquisa histórica no IPHAN. Rio de Janeiro: IPHAN, Copedoc, 2008.

FERREIRA, Rodrigo de Almeida. Qual a relação entre História Pública e Ensino de História. In: Que História Pública queremos? Rio de Janeiro: Letra e Voz, 2018. (Versão Kindle).

FILHO, Manuel Ferreira Lima; ECKERT, Cornelia; BELTRÃO, Jane Felipe (orgs.). Antropologia e patrimônio Cultural: Diálogos e Desafios contemporâneos. Nova Letra, S/d. Disponível em: http://livroaberto.ufpa.br/jspui/bitstream/prefix/442/1/CapitulodeLivro_EducacaoPatrimonial Perspectivas.pdf, acesso em 1/10/2019.

FUNARI, Pedro Paulo \& PELEGRINI, Sandra C. A. Políticas Patrimoniais no Brasil: impasses e realizações. Patrimônio Histórico e Cultural. Rio de Janeiro: Zahar Ed., 2006.

GONÇALVES, José Reginaldo Santos. O patrimônio como categoria de pensamento. In: ABREU, Regina; CHAGAS, Mário; (orgs.). Memória e patrimônio: ensaios contemporâneos. 2. Ed. Rio de Janeiro: Lamparina, 2009. p. 25-33

GONÇALVES, Janice. Da educação do público à participação cidadã: Sobre ações educativas e patrimônio cultural. In: https://revistas.unilasalle.edu.br/index.php/Mouseion/article/view/1860 
GRUNBERG, Evelina. Educação patrimonial: utilização dos bens culturais como recursos educacionais. In: Museologia social. Porto Alegre, EU - Secretaria Municipal de Cultura, 2002, p.95- 110 .

Manual de atividades práticas de educação patrimonial. Brasília, DF: IPHAN, 2007. $24 \mathrm{p}$.

HARTOG, François. Tempo e Patrimônio. Varia História, Belo Horizonte, v.22, n. 36, 2006, p. $261-273$.

HORTA, Maria de Lourdes P; GRUNBERG, Evelina; MONTEIRO, Adriane Q. Guia básico de educação patrimonial. Brasília: IPHAN, 1999.

HORTA, Maria de Lourdes Parreiras. Fundamentos da educação patrimonial. In: Ciências \& Letras. Revista da Faculdade Porto-Alegrense de Educação, Ciências e Letras, Porto Alegre, n. 27, jan/jun, 2000, p. 25-35.

JIMÉNEZ-RAMÍREZ, Magdalena; DEL POZO SERRANO, Francisco José. Memória, património educativo e espaços virtuais de aprendizagem. Uma experiência na Universidade de Granada. Revista Tempo e Argumento, Florianópolis, v. 8, n. 19, p. 34 - 59. set./dez. 2016. Disponível em http://revistas.udesc.br/index.php/tempo/article/view/2175180308192016034/6349

KNAUSS, Paulo. Quais os desafios dos museus em face da história pública? In: Que História Pública queremos? Rio de Janeiro: Letra e Voz, 2018. (Versão Kindle)

MATTOZZI, Ivo. Una epistemologia y una metodologia de la historia para la didáctica. Revista de Educação Histórica - REDUH. N.01/ Julh. - Nov.2012. Disponível em: hppt://www.lapeduh.ufpr.br. Acessado em: 05/03/2013, às 20h.

MENESES, José Newton Coelho. Todo patrimônio é uma forma de história pública? In: Que História Pública queremos? Rio de Janeiro: Letra e Voz, 2018. (Versão Kindle).

ORIÁ, Ricardo. História Pública e monumentos: a narrativa visual do passado nacional. In: ALMEIDA, Juniele Rabêlo de; MENESES, Sônia (org.). História pública em debate: patrimônio, educação e mediações do passado. São Paulo: Letra e Voz, 2018.

POLLACK, Michael. Memória e identidade social. Estudos Históricos. Rio de Janeiro, v. 5, n. 10,1992 , p. 200-212.

QUIJANO, Anibal. A colonialidade do saber: eurocentrismo e ciências sociais. Perspectivas latino-americanas. CLACSO, Buenos aires, 2005

RÜSEN, Jörn. Didática da História: Passado, Presente e Perspectivas a partir do caso alemão. In: BARCA, Isabel MARTINS, Estevão de R.; SCHMIDT, Maria A; (Orgs). Jörn Rüsen e o ensino de História. pp. 23-40. Curitiba: Editora UFPR, 2010. 
No caminho para uma pragmática da cultura histórica. In: Aprendizagem histórica: fundamentos e paradigmas. Curitiba: W.A. Editores, 2012.

Cultura faz sentido. Rio de Janeiro: Editora Vozes, 2014.

Recebido em: 08/10/2019

Aprovado em: 07/04/2020 